\title{
A new planning model to support logistics service providers in selecting mode, route, and terminal location
}

\author{
Nathan Huynh, Ph.D., Assistant Professor \\ Fateme Fotuhi, M.Sc. \\ University of South Carolina, Columbia, SC USA
}

\begin{abstract}
In this paper, we address thefreight network design problem. A mixed integer linear program is formulated to help logistics service providers jointlyselect the best terminal locations among a set of candidate locations, shipping modes, and route for shipping different types of commodities. The developed model isapplied to two different networksto show its applicability. Results obtained from CPLEX for the case studiesare presented, and the benefit of the proposed model is discussed.
\end{abstract}

Key words: Intermodal transport; Freight logistics; Network design; Facility location; Routing; Mode choice

\section{INTRODUCTION}

Over the last 50 years, international trade in manufactured goods grew 100 fold, straining global supply chains and the underlying support infrastructure (IBM, whitepaper). Consequently, shippers and receivers are forced to look for more efficient ways to move their products. The process of moving products (i.e. freight) from one point to another is known as freight transportation. Typically, when freight is transported over long distances, more than one mode is used due to limited access at the receiving end (e.g. no rail access at distribution center or warehouse). Other reasons for considering more than one mode in transporting freight include (Eberts, 1998): (1) lowering overall transportation costs by allowing each mode to be used for the portion of the trip to which it is best suited, (2) reducing congestion and the burden on overstressed infrastructure components, and (3) reducing energy consumption and contributing to improved air quality and environmental conditions. When there are more than one mode involved in delivering freight (known as intermodal freight transportation), the cost of each mode, the trip time on each mode, the time that it takes to transfer to another mode, and the location of that transfer play a critical role in the overall efficiency of the process. One of the reasons for the inefficiencies in intermodal freight transportation is the lack of planning on where to locate intermodal facilities in the transportation network and to expand the surrounding infrastructure to accommodate newly generated traffic. This paper addresses this need by proposing a model that considersthe intermodal terminal location jointly with other criteria.
Figure 1 illustrates a simple intermodal freight transportation network that consists of shipping origins and destinations, highway network that connects all origins and all destinations, limited number of intermodal terminals, and rail, air, or barge networks that connect the various intermodal terminals; an intermodal terminal is the location where freight is transferred between different modes. In this illustration, it can be seen that freight can be shipped directly from an origin to a destination using only the highway mode. Alternatively, freight can be shipped first to a nearby intermodal terminal, then shipped to another intermodal terminal near the destination using another mode such as rail, air, or barge, and finally delivered to the destination using the highway mode.It is evident that the optimal method of shipping will depend on the distance between the origin and destination, the proximity of intermodal terminals to the origin and destination, the type of intermodal terminal available (i.e. rail, air, or barge), and the transport and transfer cost. This paper takes the perspective of logistics service providers who are tasked to serve a multiregional customer base (Ishfaq, 2010). Of particular interest to these decision makers is the managementof shipments between origins and destinationthrough the use of different modes, routes, as well as logistic hubs. At a strategic planning level, these service providers need to develop long-term policies on terminal locations, modes, and routes to lower costs.

To assist these logistics service providers with their decision making, this paper proposes a new model that jointly considers a number of factors: establishing a predefined number of intermodal terminals at strategic locations, type of intermodal terminals that should be created, shipping mode, and route for 


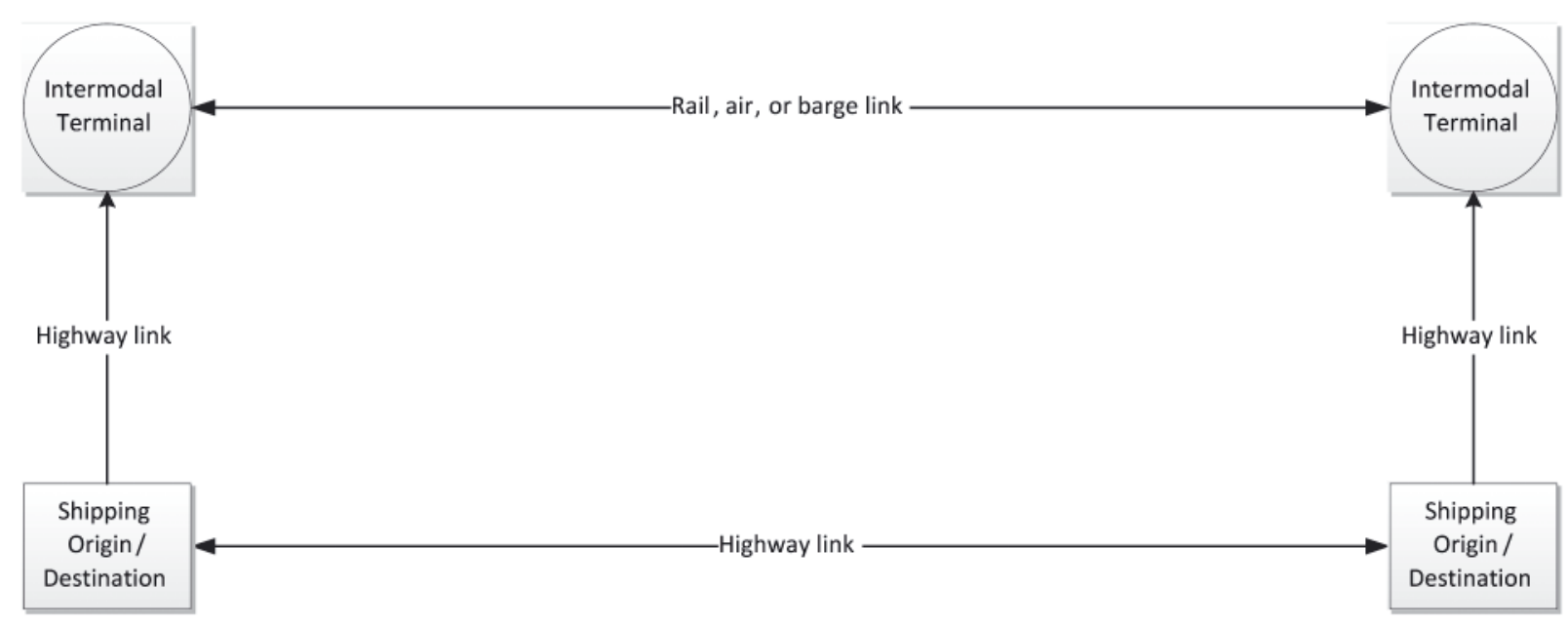

Fig. 1. Illustration of an intermodal freight network

shipping commodities. Additionally, it is envisioned that the proposed model could be used by thedecision maker to estimate how many intermodal terminals are needed to maximize return on investment. To our knowledge, this is the first model that addresses multiple decisions jointly in the design of the intermodal freight network.

The remainder of this paper is organized as follows. Section 2 provides a review of related research, followed by the formulation of the proposed mixed integer linear programming model in Section 3. Section 4 discusses the computational results. Lastly, Section 5 provides concluding remarks and plans for future research.

\section{PRIOR RESEARCH}

The following summarizes previous studies on two related topics: identifying optimal location for intermodal terminals, and selecting optimal mode and route for shipping freight.

Rutten (1995) was the first to study where to locate new intermodal terminals with and without existing intermodal terminals. In his research, terminals were selected according to their attraction for freight movement so the network could have daily trains between terminals. He evaluated the impact of locating a new terminal on existing terminals' performance. Meinert et al.'s work (1998) involved locatinga rail intermodal terminal among several potential sites in a network using simulation. Macharis et al. (1999) used multi criteria decision making to find where to build a new barge terminal in Belgium. They defined a hierarchy of criteria for four candidate locations and then used PROMETTHE (Preference Ranking Organization Method for Enrichment Evaluations) to find the best candidate. Similarly, Arnold et al. (2001) proposed a mixed integer model to design a rail/road network in Belgium. In their model, two decisions were taken simultaneously. The first decision involved determining which terminals should be opened among a set of potential candidates. The other decision involved allocatingthe demand betweeneach origin-destination (OD) to either use an intermodal terminal or a direct shipment (hence using just one mode). Groothedde etal. (2005) compared a road/barge intermodal option with a unimodal road network in a consumer goods market. Their heuristic found the best location for intermodal hubs. They concluded that using a hubbased intermodal network is more efficient than a unimodal road network. More recently, Limbourge et al. (2009) developed a model based on the traditional p-hub median problem to find the best location for intermodal terminals on a rail/road network. In addition to considering transportation cost, they considered a variable transshipment cost in their objective function. The unit transshipment cost relates to volume of flow passes over each intermodal hub. Ishfaq et al. (2010) improved the previously studied intermodal distribution networks by considering a larger intermodal network of road, rail, and air. They integrated service time requirements into a hub location and allocation of demands to selected hubs. They also considered three different types of costs: fixed cost of opening an intermodal hub, modal connectivity cost, and transportation cost.

In freight logistics, the tactical decisions typically involve deciding which mode to use and what routeto take to minimize trip time and to ensure reliable delivery (Crainic 2002). Barnhart et al. (1993) discussed methods to compare intermodal routing of rail/road freight network versus unimodal road transport. Least cost routes were selected based on the transportation cost per trailer and per flatcar, respectively. Boardman et al. (1997) proposed a decision support system to help decision makers find the best combination of mode and least cost route for transporting goods. Bookbinder et al. (1998) used simulation to find the best route for moving containers from Canada to Mexico. Boussedjra et al. (2004) found the least cost travel path between each origin-destination pair in an intermodal transportation network considering time constraints. Song et al. (2007) developed a model to find the least cost path between each OD pair while minimizing total transportation, transshipment, and holding costs. They considered a time constraint on delivering shipments to their destinations. To make the problem more realistic, Grasman (2006) proposed a dynamic programing approach to find the least cost path considering both delivery time constraint and total transportation cost. Chang (2008) improved the traditional intermodal freight routing problem by considering more than one commodity in his model. He proposed a multi-objective model for his multi-commodity network to find the best route for each OD pair. His model simultaneously minimized total transportation cost and travel time. In the most recent study, Ayar et al. (2012) developed a mixed integer model for an intermodal multi-commodity road/maritime network to find the best route for each OD pair. Their model considered timewindow constraints to deliver each commodity to its final destination and total transportation and stocking costs.

Table 1 provides a comparison of previous research's scope vs. our proposed model's scope. As shown, the work byIshfaqet al. (2010) and Ayar et al. (2012) are the two closest related studies. Our model's contribution to the literature is the ability to deal with different combinations of modes (truck, 
Tab. 1. Comparison of previous research's scope vs. proposed model's scope

\begin{tabular}{|c|c|c|c|c|c|}
\hline \multirow{2}{*}{ Research } & \multicolumn{3}{|c|}{ Decisions } & \multirow{2}{*}{ Type of mode } & $\begin{array}{c}\text { Direct shipping } \\
\text { option }\end{array}$ \\
\cline { 2 - 6 } & $\begin{array}{c}\text { Terminal } \\
\text { location }\end{array}$ & $\begin{array}{c}\text { Mode } \\
\text { choice }\end{array}$ & routing & Road/rail & $*$ \\
\hline Arnold et.al (2001) & $*$ & & & Road/barge & $*$ \\
\hline Groothedde et al. (2005) & $*$ & & & Air/rail/truck/barge & $*$ \\
\hline Chang (2008) & & & $*$ & Road/rail & $*$ \\
\hline Limbourge et.al (2009) & $*$ & & & Road/rail/air & $*$ \\
\hline Ishfaq et.al (2010) & $*$ & $*$ & & Road/maritime & \\
\hline Ayar et.al (2012) & & & $*$ & Any combination of modes & $*$ \\
\hline Proposed model & $*$ & $*$ & $*$ & & \\
\hline
\end{tabular}

rail, air, barge). This feature provides more options for the decision makers and subsequently a more robust intermodal freight network. Though Ishfaqet et al. (2010) considered three modes in their work, their model will not allow for different combination of modes. Another contribution of our model is the integration of terminal location, terminal type, mode, and routejointly. In Ishfaq et al.'s work (2010), they did not consider route. The key difference between our model and that of Ayar et al. (2012) is that our model allows decision makers to identify the location and type of new intermodal terminals to establish in the network.

\section{MATHEMATICAL FORMULATION}

Within the context of this research, an intermodal freight network location-routing problem (IFNLRP) is considered. This network is represented by a graph $\mathrm{G}(\mathrm{N}, \mathrm{A})$ where $\mathrm{N}=\{\mathrm{C}, \mathrm{D}\}$ represents the set of nodes and A represents the set of edges. The node set consists of these two subsets: $\mathrm{C}$ and $\mathrm{D}$ where $\mathrm{C}$ represents the cities and $\mathrm{D}$ represents the candidate intermodal terminal locations in the network. A set of commodities in containers is to be routed according to known demands $\mathrm{f}_{\mathrm{w}}$ between each Origin-Destination (OD) pair $\mathrm{w} \in \mathrm{W}$. Among a set of $\mathrm{D}$ candidate intermodal terminal locations, at most $p \in D$ terminals will be located in the network. Binary decision variables $\mathrm{O}_{\mathrm{d}}^{\mathrm{t}}$ are used to identify the mode $t$ is to be served at terminal d (i.e. rail terminal or air terminal). Each commodity can be delivered to its destination directly using trucks (single mode) or via intermodal facilities (multi modes). Thus, multiple modes T are considered, with $\mathrm{t} \in \mathrm{T}$ denoting the mode to be used ( $\mathrm{t}=0$ is highway, $\mathrm{t}=1$ is rail, $t=2$ is air, and $t=3$ is barge). The fixed cost of opening a terminal, transfer cost and transportation cost are the three types of costs considered in the IFNLRP.The transfer cost is the cost of moving a container through a terminal and the exact cost is dependent on the terminal type. In this work, the transfer cost is considered as a different percentage of the fixed cost for each mode. The transportation cost is the cost of moving a container along the rail or truck links and is based on travel distance. This cost differs for different modes, with barge being the cheapest and air the costliest. For each OD pair that has demands, all available connecting routes are considered, with and without going through an intermodal facility. The model finds the least cost routes. Therefore, our proposed model consists of determining jointly the mode, route, and location to site and type of intermodal facility to operate to satisfy demands at minimum cost. The model is formulated as follows:
Sets:

$\mathrm{T}-$ set of modes

C - set of cities

D - set of candidate intermodal terminal locations

A - set of Arcs

W - set of OD pairs

\section{Parameters:}

$\mathrm{p}-$ Number of intermodal terminals to be opened

$\mathrm{f}_{\mathrm{w}}-$ Quantity of demand for OD pair $\mathrm{w}$

$\mathrm{C}^{\mathrm{W}}{ }^{\mathrm{t}}$ - Transportation rate per container for mode $\mathrm{t}$

$\mathrm{L}^{\mathrm{t}}$ - Capacity of a container for mode $\mathrm{t}$

$\mathrm{MC}_{\mathrm{d}}^{\mathrm{t}}$ - transfer cost of changing to a different mode $\mathrm{t}$ at terminal d

$\mathrm{F}_{\mathrm{d}} \quad$ - fixed cost of opening and operating terminal $\mathrm{d}$

$\mathrm{CL}_{\mathrm{ij}}^{\mathrm{t}}$ - Total commodity flow over link $(\mathrm{i}, \mathrm{j})$ using mode $\mathrm{t}$

$\mathrm{d}_{\mathrm{ij}}$ - total distance for link $(\mathrm{i}, \mathrm{j})$

\section{Decision Variables:}

$\mathrm{y}_{\mathrm{d}}=\left\{\begin{array}{c}1, \text { If terminal } \mathrm{d} \text { is to be sited } \\ 0, \text { else }\end{array}\right.$

$\mathrm{O}_{\mathrm{d}}^{\mathrm{t}}=\left\{\begin{array}{c}1, \text { If mode } \mathrm{t} \text { is served by terminal d } \\ 0, \text { else }\end{array}\right.$

$\mathrm{x}_{\mathrm{ijw}}^{\mathrm{t}}$ - Proportion of demand of OD pair w shipped over link $(i, j)$ using mode $t$

Model formulation:

$$
\begin{gathered}
\min \sum_{\mathrm{d} \in \mathrm{D}} \mathrm{F}_{\mathrm{d}} \mathrm{y}_{\mathrm{d}}+\sum_{\mathrm{d}} \sum_{\mathrm{t}} \mathrm{MC}_{\mathrm{d}}^{\mathrm{t}} \mathrm{O}_{\mathrm{d}}^{\mathrm{t}}+\sum_{(\mathrm{i}, \mathrm{j}), \mathrm{t} \in \mathrm{T}} \mathrm{C}(\mathrm{i}, \mathrm{j}, \mathrm{t}) \\
\text { s.t.: } \sum_{\mathrm{d}} \mathrm{y}_{\mathrm{d}} \leq \mathrm{p} \\
\mathrm{O}_{\mathrm{d}}^{\mathrm{t}} \leq \mathrm{y}_{\mathrm{d}}, \forall(\mathrm{d}, \mathrm{t}) \\
\sum_{\mathrm{d}^{\prime} \in \mathrm{D}} \sum_{\mathrm{w}} \mathrm{x}_{\mathrm{d}^{\prime} \mathrm{dw}}^{\mathrm{t}} \leq|\mathrm{N}|^{2} \mathrm{O}_{\mathrm{d}}^{\mathrm{t}}, \forall(\mathrm{t}, \mathrm{d}) \\
\mathrm{f}_{\mathrm{ij}}^{\mathrm{t}}=\sum_{\mathrm{w}} \mathrm{x}_{\mathrm{ijw}}^{\mathrm{t}} \mathrm{f}_{\mathrm{w}}, \forall(\mathrm{w}, \mathrm{t})
\end{gathered}
$$

$\sum_{j} x_{i j w}^{t}-\sum_{j} x_{j i w}^{t}=\left\{\begin{array}{c}1, \text { If } i \text { is the origin for OD pair } w \\ -1, \text { If } i \text { is the destination for OD pair } w \\ 0, \text { else }\end{array}\right.$

$\sum_{\mathrm{t}} \sum_{\mathrm{d}^{\prime}} \mathrm{x}_{\mathrm{dd}^{\prime} w}^{\mathrm{t} w}+\sum_{\mathrm{i}} \mathrm{x}_{\mathrm{idw}}^{\mathrm{t}_{0}}-\sum_{\mathrm{t}} \sum_{\mathrm{d}^{\prime}} \mathrm{x}_{\mathrm{d}^{\prime} \mathrm{dw}}^{\mathrm{t}}-\sum_{\mathrm{j}} \mathrm{x}_{\mathrm{djw}}^{\mathrm{t}_{0}}=0$ 


$$
\begin{gathered}
\sum_{\mathrm{t}} \sum_{\mathrm{d}^{\prime}} \mathrm{x}_{\mathrm{dd}^{\prime} \mathrm{w}}^{\mathrm{t}}-\sum_{\mathrm{t}} \sum_{\mathrm{d}^{\prime}} \mathrm{x}_{\mathrm{d}^{\prime} \mathrm{dw}}^{\mathrm{t}}=0, \forall \mathrm{d} \in \mathrm{D} \\
\mathrm{CL}_{\mathrm{ij}}^{\mathrm{t}}=\sum_{\mathrm{w}} \mathrm{x}_{\mathrm{ijw}}^{\mathrm{t}} \mathrm{f}_{\mathrm{w}}, \forall(\mathrm{i}, \mathrm{j}) \in \mathrm{A}, \mathrm{t} \in \mathrm{T} \\
\mathrm{C}(\mathrm{i}, \mathrm{j}, \mathrm{t})=\frac{\mathrm{CL}_{\mathrm{ij}}^{\mathrm{t}}}{\mathrm{L}^{\mathrm{t}}} \mathrm{C}^{\prime t} \mathrm{~d}_{\mathrm{ij}}, \forall(\mathrm{i}, \mathrm{j}) \in \mathrm{A}, \mathrm{t} \in \mathrm{T} \\
\mathrm{y}_{\mathrm{d}}, \mathrm{o}_{\mathrm{d}}^{\mathrm{t}} \in\{0,1\}, 0 \leq \mathrm{x}_{\mathrm{jjw}}^{\mathrm{t}} \leq 1
\end{gathered}
$$

The first term in objective function (1) is the fixed cost of siting and operating an intermodal terminal $\mathrm{d}$, the second term is the transfer cost of changing to a different mode $t$ at terminal $\mathrm{d}$, and the third term is the transportation cost of transporting containers over each link of the network using mode t. Constraint 2 requires that not more than $\mathrm{p}$ intermodal terminals are to be opened. It should be noted that at least two terminals needed to be opened. That is, the intermodal shipping option (e.g. via truck/rail) requires at least two rail terminals because only trucks can access the node and origin nodes. Constraint (3) ensures operation of mode $t$ at terminal $\mathrm{d}$ if the terminal is selected to be opened. Constraint (4) allows links terminated or originated from terminal $\mathrm{d}$ to be selected for a shipment using mode $t$ if mode $t$ is selected to be operated at terminal $d$. Total flow over link $(i, j)$ for mode $t$ is calculated using Constraint (5). Constraint (6) ensures flow conservation at each node. Regarding the flow conservation condition, the flow-in should equal to flow-out for all nodes that are not an origin or destination node of any of OD pairs. For the origin node, all flow should emanate from it, and for the destination node all flow should terminate into it. Similarly, Constraints (7) and (8) deal with the flow conservation at each terminal. Constraint (9) computes the flow between two intermodal terminals. Finally, Constraint (10) determines the transportation cost of moving containers between each pair of cities/terminals.

\section{COMPUTATIONAL RESULTS}

To demonstrate the applicability of the developed model, two case studies were conducted. The first case study uses a small hypothetical network with 7 nodes and 3 candidate locations for intermodal terminals. Highway, rail, and air are the three available modes on this network. Data for this case studywere randomly generated. The second case study uses a larger network with 47 nodes and 14 candidate locations for intermodal terminals. This network includes major U.S. cities and key interstate highways that connect them. Highway and rail are the two modes considered for this network.For both case studies, the experiments were designed to investigate the effect of number, location, and type of intermodal terminals and costs on the performance of the intermodal freight network (i.e. total cost). Results were obtained using CPLEX.

\section{Case study 1}

Figure 2 shows the network for this case study. The numbers next to each link denote the distance of that link. Nodes A, B and $\mathrm{C}$ are the candidate intermodal terminal locations witha fixed opening cost of $\$ 700, \$ 800$ and $\$ 600$, respectively. As done in Ishfaq et al's work, (2010), we considered the transfer cost for highway, rail and air to be $10 \%, 20 \%$ and $30 \%$ of a terminal's fixed cost. The commodities are considered to be shippedbetween 10 OD pairs. Table 2 shows the shippingdata for these OD pairs. Demands are shipped using containers that have capacity of $80,000 \mathrm{lbs}$. We considered $\$ 0.2$ and $\$ 2$ as the transportation rate per container per mile for rail and road, respectively (Luo et al. 2003). The shipping rate for air is $\$ 3$ per container per mile. To assess the efficiency of using intermodal transport, 2 scenarios are considered for this case study. In the first scenario, we considered the possibility of opening at most 2 intermodal terminals in the network. In this scenario, we assumed that the decision maker has a budget that limits the maximum number of terminals he can build. In the second scenario (the base case), all containers are to be transported using only the highway mode.

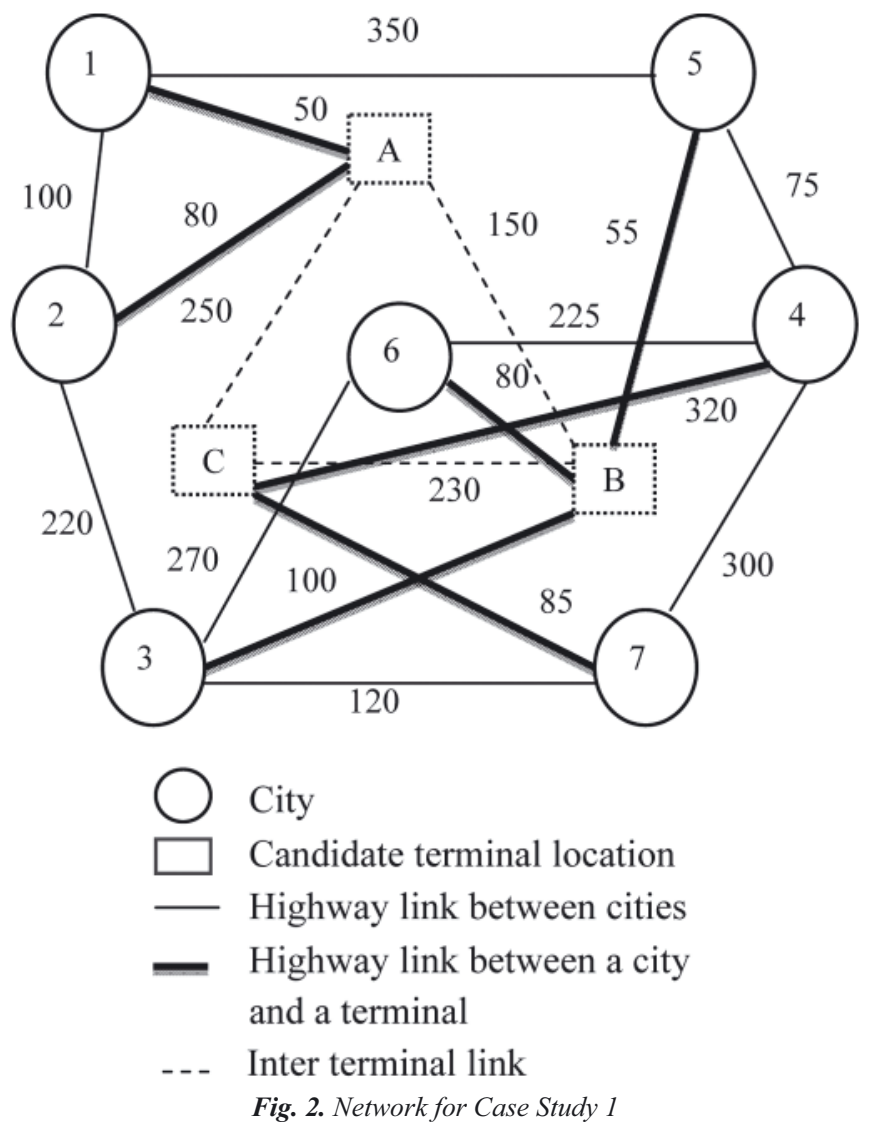

Tab. 2. Shipping data for Case Study 1

\begin{tabular}{|c|c|c|c|}
\hline Index & Origin & Destination & Demand (lbs) \\
\hline 1 & 1 & 4 & 132,000 \\
\hline 2 & 1 & 3 & 125,000 \\
\hline 3 & 2 & 6 & 130,000 \\
\hline 4 & 2 & 7 & 120,000 \\
\hline 5 & 3 & 2 & 140,000 \\
\hline 6 & 3 & 7 & 130,000 \\
\hline 7 & 4 & 1 & 80,000 \\
\hline 8 & 4 & 5 & 110,000 \\
\hline 9 & 5 & 7 & 120,000 \\
\hline 10 & 6 & 1 & 90,000 \\
\hline
\end{tabular}

The results of case study 1 are shown in Table 3. Since the network used for this case study is relatively small, all results were obtained in about 1 second from CPLEX. There is only one optimal route for each OD pair for both scenarios. Terminals A and B are selected as rail terminals. The network cost (i.e. optimal objective function value) for scenario 1 is $\$ 21,991$, whereas the network cost for scenario 2 is $\$ 25,177$. These results suggest that it would be more cost effective to 
ship freight if the network were to have two rail intermodal terminals at nodes $\mathrm{A}$ and $\mathrm{B}$ and that freight are shipped via these terminals. In some cases, where there is a direct highway link between a pair of cities that are in close proximity, using just highway modeis more cost effective.

Tab. 3. Results of case study 1

\begin{tabular}{|c|c|c|}
\hline $\begin{array}{c}\text { OD } \\
\text { Index }\end{array}$ & $\begin{array}{c}\text { Optimal route for } \\
\text { scenario 1 }\end{array}$ & $\begin{array}{c}\text { Optimal route for } \\
\text { scenario 2 }\end{array}$ \\
\hline 1 & $1-\mathrm{A}-\mathrm{B}-5-4$ & $1-5-4$ \\
\hline 2 & $1-\mathrm{A}-\mathrm{B}-3$ & $1-2-3$ \\
\hline 3 & $2-\mathrm{A}-\mathrm{B}-6$ & $2-3-6$ \\
\hline 4 & $2-3-7$ & $2-3-7$ \\
\hline 5 & $3-2$ & $3-2$ \\
\hline 6 & $3-7$ & $3-7$ \\
\hline 7 & $4-5-\mathrm{B}-\mathrm{A}-1$ & $4-5-1$ \\
\hline 8 & $4-5$ & $4-5$ \\
\hline 9 & $5-\mathrm{B}-3-7$ & $5-4-7$ \\
\hline 10 & $6-\mathrm{B}-\mathrm{A}-1$ & $6-3-2-1$ \\
\hline $\begin{array}{l}\text { Selected terminals for scenario } 1: \text { A and B selected as rail } \\
\text { terminals. } \\
\text { Total cost for scenario 1: } \$ 21,991\end{array}$ \\
Total cost for scenario 2: \$25,177 \\
\hline
\end{tabular}

\section{Case study 2}

Figure 3 shows the network for this case study. As mentioned, this network considered 47 major U.S. cities and 14 of these 47 cities are considered as candidate locations for intermodal terminals. A total of 118 highway and rail links connect these cities to each other. Google Maps was used to find the distances between these cities. Transfer and transportation costs for rail and highwayare the same as case study 1 . The other data required for the model include the demand between OD pairs, and fixed costs of opening a terminal were generated randomly.
In contrast with case study 1 , there is no predefined number of candidate terminals. Twenty (20) scenarios were conducted to find the optimal number of intermodal terminals, type, and locations, as well as routes for the different OD pairs. For case study 2, the experiment design involves finding the optimal number of terminals to open to reduce the total cost. The results of case study 2 are shown in Table 4 (an asterisk denotes the scenario with the optimal cost). For example, with 5 OD pairs, scenario 1 yields the lowest cost. The results shown in Table 4 provide some important insights: (1) increasing number of OD pairs that have shipments between them increase the optimal number of intermodal terminals; (2) the higher the number of intermodal terminals the lower the total cost, but only up to a certain threshold, beyond which yield no reduction in cost (e.g. with 50 OD pairs, it is best to have 5 rail terminals rather than 4 , but there is no benefit to having 6); and (3) intermodal terminals are more likely needed for shipments going from the Southeast region of the U.S. to the Northwest than Southeast to Northeast. An example of the optimal route for the scenario with 5 OD pairs is as follows:

1. (NY,NO): NY-BLT-PIT-CIN-NSH-MEM-NO

2. (TMP,HOU): TMP-ORL-ATL-MEM-NO-HOU

3. (BOS,CLT): BOS-NY-BLT-CLT

4. (BUF,DEN): BUF-CLV-COL-IND-SLT-KC-OM-BLDEN

5. (LV, PIT):LV-BL-OM-KC-SLT-IND-COL-CLV-PIT

The first 3 OD pairs uses truck for their shipments while the last two usethe rail/road combination. These results indicate that the intermodal option is more cost effectivewhen shipping cargo over longer distances.

As expected, the execution times increase as the number of OD pairs increases, with a maximum execution time of 30 seconds for 100 OD pairs. Since the IFNLRP is NP-hard, the execution times are expected to grow exponentially with the problem size. Thus, in order to solve large-sized problems, heuristics will be needed and will be the focused of our subsequent work. In this paper, our focused is in developing the model formulation and gaining insight into the problem through small-scale problems.

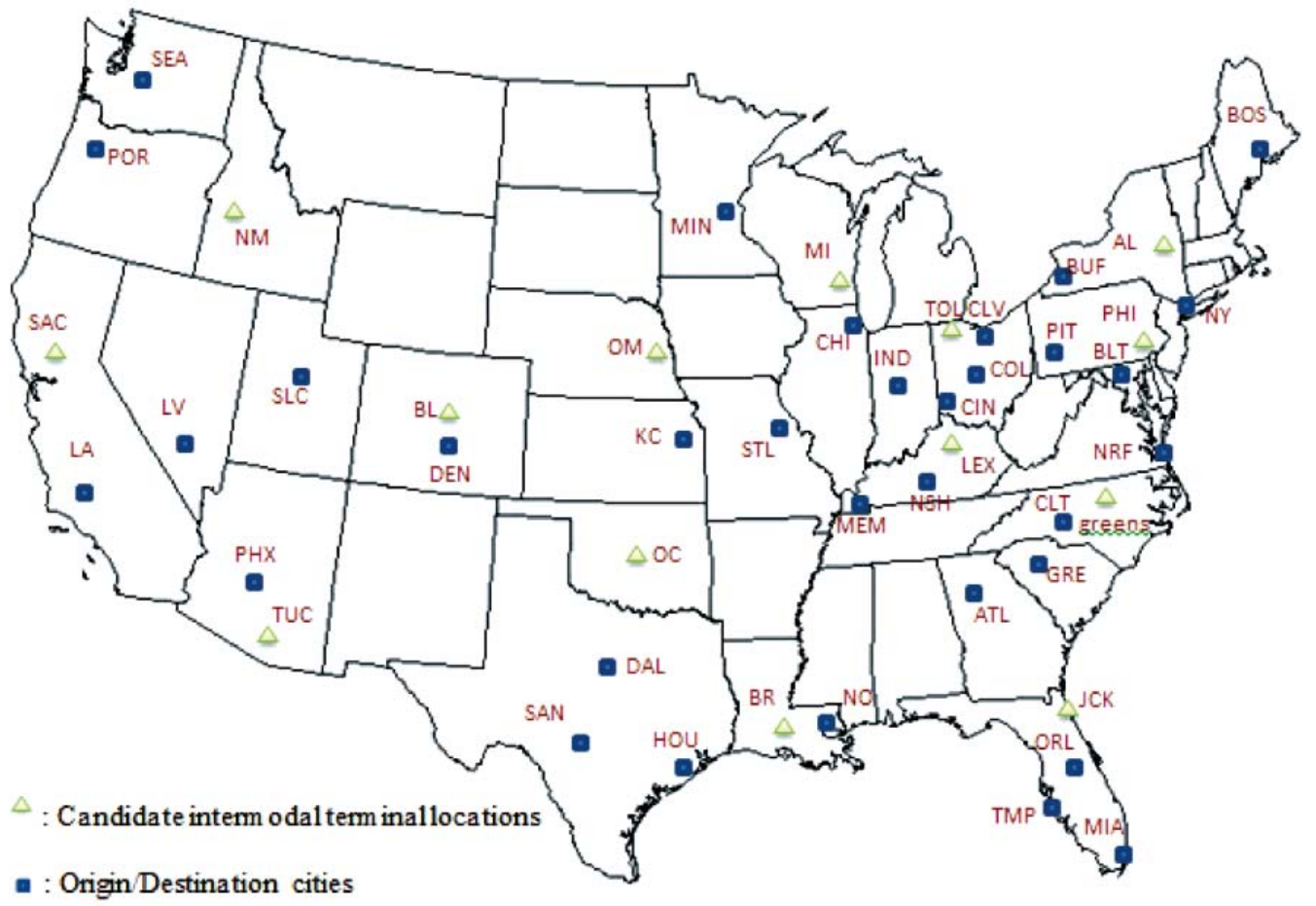

Fig. 3. Network for Case Study 2 
Tab. 4. Results ofCase Study 2

\begin{tabular}{|c|c|c|c|c|}
\hline Scenario & $\begin{array}{c}\text { \# of OD } \\
\text { pairs }\end{array}$ & $\begin{array}{c}\text { Maximum Number of rail } \\
\text { terminals to be opened }\end{array}$ & Total cost [\$] & $\begin{array}{c}\text { Execution time } \\
\text { [sec] }\end{array}$ \\
\hline 1 & 5 & 2 & $30875^{*}$ & $1: 37$ \\
\hline 2 & 5 & 3 & 30875 & $2: 30$ \\
\hline 3 & 10 & 2 & 61982 & $5: 18$ \\
\hline 4 & 10 & 3 & 61139 & 6.24 \\
\hline 5 & 10 & 4 & $53952^{*}$ & 6.96 \\
\hline 6 & 10 & 5 & 53952 & 6.30 \\
\hline 7 & 15 & 2 & 106186 & 6.15 \\
\hline 8 & 15 & 3 & 96525 & 6.78 \\
\hline 9 & 15 & 4 & $84503 *$ & 6.89 \\
\hline 10 & 15 & 5 & 84503 & 6.9 \\
\hline 11 & 30 & 4 & 184077 & 6.85 \\
\hline 12 & 30 & 5 & $182129 *$ & 10.38 \\
\hline 13 & 30 & 6 & 182129 & 12.74 \\
\hline 14 & 50 & 4 & 301325 & 15.48 \\
\hline 15 & 50 & 6 & $295243 *$ & 15.58 \\
\hline 16 & 50 & 5 & 295243 & 14.33 \\
\hline 17 & 70 & 5 & $389167^{*}$ & 23.71 \\
\hline 18 & 70 & 5 & 389167 & 22.34 \\
\hline 19 & 100 & $550101 *$ & 30 \\
\hline 20 & 100 & 550101 & \\
\hline & & 5 & & \\
\hline
\end{tabular}

\section{SUMMARY AND CONCLUSION}

This study has developed a location-routing intermodal freight network design model that can simultaneously optimize the number, location, and type of intermodal terminals, as well as shipping modes and routes while satisfying demands at minimum cost. The model is formulated as a mixed integer linear program and can be solved using the CPLEX solver. The model was tested using two case studies. The results of the two case studies corroborated previous findings that shippingfreight using the intermodal option is more cost effective than using the unimodal option (i.e. highway only). An interesting insight gained from the results is that as the number of shipments between OD pairs increase, more intermodal terminals are needed; however, only up to a certain number. The contribution of the developed model is that it could be used by logistics service providersto determine the number, location, and type of intermodal terminals needed to expedite shipping and minimize costs. It could also be used to predict the shipping mode and route (assuming shippers will seek to minimize cost) so that the necessary infrastructure could be upgraded to accommodate expected new traffic. In future work, the authors intend to improve upon this study by considering delivery time constraint and the impact of congestion.

\section{REFERENCES}

1. Arnold, P., Peeters, D., Thomas, I., and Marchand, H.: Pour unelocalisationoptimale des centre de transbordementintermod aux entre re' seaux de transport: formulation et extensions. The Canadian Geographer, Vol. 45, No. 3, 427-36, 2001.

2. Arnold, P., Peeters, D., and Thomas, I.: Modeling a Rail/Road transportation system. Transportation Research Part E, Vol. 40, 255-270, 2004.
3. Ayar, B., and Yaman, H.: An intermodal multicommodity routing problem with scheduled services. Computational optimization and Application, Vol. 53, 131-153, 2012.

4. Barnhart, C., and Ratliff, H.: Modeling intermodal routing. Journal of Business Logistics, Vol.14, 205-223, 1993.

5. Bektas, T., and Crainic, T. G.: A brief overview of intermodal transportation. Interuniversity Research Center on Enterprise Networks, Logistics and Transportation, 2007.

6. Boardman, B.S., Malstrom, E.M., Butler, D.P., and Cole, M.H.: Computer assisted routing of intermodal shipments. Proceedings of 21st International Conference on Computers and Industry Engineering, vol. 33, No. 1, 311-314, 1997.

7. Boussedjra, M., Bloch, C., and El Moudni, A.: An exact method to find the intermodal shortest path. Proceedings of the IEEE International Conference on Networking, Sensing \& Control, 1075-1080, 2004.

8. Chang, T.S.: Best routes selection in international intermodal networks. Computer and Operations Research, Vol. 35, 28772891, 2008.

9. Crainic, T. G.: A survey of optimization models for long-haul freight transportation. Handbook of Transportation Science R.W. Hall (Ed.), 2nd Edition, Kluwer, 2002.

10.Crainic, T. G., and Kim, K. H.: Intermodal Transportation. C. Barnhart and G. Laporte (Eds.), Handbook in OR \& MS, Vol. 14,2007

11.Eberts, R.: Principles for Government Involvement in Freight Infrastructure.In Transportation Research Board Special Report 252: Policy Options for Intermodal Freight Transportation, 1998.

12.Grasman, S.E.: Dynamic approach to strategic and operational multimodal routing decisions. International Journal of Logistic Systems and Management, Vol. 2, 96-106, 2006.

13.Groothedde, B., Ruijgrok, C., and Tavasszy, L.: Towards collaborative, intermodal hub networks: A case study in the fast moving consumer goods market. Transportation Research Part E: Logistics and Transportation Review, Vol. 41, No. 6, 567-583, 2005. 
14.Guerra, L., Murino, T., and Romano. E.: A heuristic algorithm for the constrained location-routing problem. International journal of systems applications, Engineering and development, Vol.4, No.1, 146-154, 2007.

15.IBM. The Case for Smarter Transportation. http://www-07.ibm. com/innovation/my/exhibit/documents/pdf/2_The_Case_For Smarter_Transportation.pdf. Accessed December $\overline{3} 1,20 \overline{1} 2$.

16.Ishfaq, $\overline{\mathrm{R}}$., and Sox, C. R.: Intermodal logistics: The interplay of financial, operational and service issues. Transportation Research Part E, Vol. 46, 926-949, 2010.

17.Limbourg, S., and Jourquin, B.: Optimal rail-road container terminal locations on the European network. Transportation Research (E), Vol. 45, No. 4, 551-563, 2009.

18.Luo, M., and Grigalunas, T. A.: A multimodal transportation simulation model for US coastal container ports. TRB 2003 annual meeting, 2003

19.Meinert, T.S., Youngblood, A.D., Taylor, G.D., and Taha, H.A.: Simulation of the railway component of intermodal transportation. Report, Arkansas University, Fayetteville, AK, 1998.

20.Rutten, B.J.C.M.: On medium distance intermodal rail transport. Ph.D. thesis, Delft University of Technology, Delft, 1995.
21.Song, H., and Chen, G.: Minimum cost delivery problem in intermodal transportation networks. Proceedings of the 2007 IEEE IEEM, 1502-1506, 2007.

22.Warsing, D.P., Souza, G.C., and Greis, N.P.: Determining the value of dedicated multimodal cargo facilities in a multi-region distribution network. European Journal of Operational Research, Vol. 133, No. 1, 81-93, 2001.

\section{CONTACT WITH THE AUTHORS}

Nathan Huynh*, Ph.D., Assistant Professor Fateme Fotuhi, M.Sc.

Department of Civil and Environmental Engineering, University of South Carolina, Columbia, SC USA.

* Corresponding Author Contact Information: Nathan Huynh

Civil \& Environmental Engineering College of Engineering and Computing University of South Carolina

300 Main Street, Columbia, SC 29208 Phone: (803) 777-8947 e-mail: huynhn@cec.sc.edu 